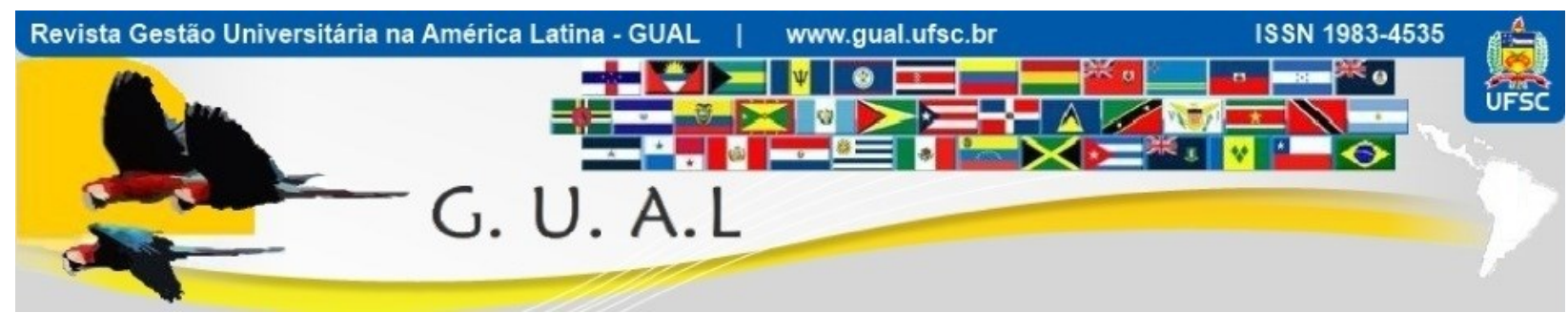

DOI: http://dx.doi.org/10.5007/1983-4535.2014v7n2p69

\title{
GESTÃO DE PROCESSO NA IMPLANTAÇÃO DE UM SISTEMA DE INFORMAÇÃO ACADÊMICA: A EXPERIENNCIA DA UFPA
}

\section{MANAGEMENT PROCESS IN THE IMPLEMENTATION OF A SYSTEM OF ACADEMIC INFORMATION: THE EXPERIENCE OF UFPA}

Milton Cordeiro Farias Filho, Doutor Universidade da Amazônia - UNAMA mcffarias@gmail.com

Maria das Graças Vilhena, Mestra Universidade Federal do Pará - UFPA vilhen@gmail.com

Durbens Martins Nascimento, Doutor

Universidade Federal do Pará - UFPA durbens.naea@gmail.com

Recebido em 20/junho/2013

Aprovado em 27/fevereiro/2014

Sistema de Avaliação: Double Blind Review

Esta obra está sob uma Licença Creative Commons Atribuição-Uso. 


\title{
RESUMO
}

O artigo relata uma pesquisa desenvolvida na Universidade Federal do Pará - UFPA, em que foi estudada a gestão do processo de implantação do sistema de informação acadêmica. Com o objetivo de identificar a forma de implantação do sistema de informação gerencial e seus efeitos na comunidade acadêmica. A pesquisa inicia com um levantamento documental. Após as análises dos documentos foi feito um suvey com 37 servidores e entrevistas estruturadas com 10 servidores. As categorias liderança, estratégia, cidadãos e sociedade, processos e pessoas; resultados, informações e conhecimentos, constaram nos instrumentos. Os resultados mostram que Universidade está em consonância parcial com a proposta de desburocratização da reforma do Estado. A conclusão é que o sistema de informação implantado mostra um avanço na gestão universitária, em duas perspectivas: uma de gestão e outra de percepção por parte dos usuários de seus serviços.

Palavra Chave: Universidade. Sistema de Informação. Gestão Acadêmica.

\begin{abstract}
The article reports on research carried out at the Federal University of Pará - libraries that hat have been studied in which the management of the implementation process of academic information system. In order to identify the form of implementation of management information system and its effects on the academic community. The research starts with a documentary survey. After analysis of the documents was made a suvey with 37 servers and structured interviews with 10 servers. The categories leadership, strategy, people and society, processes and people, results, information and knowledge, consisted in the instruments. The results show that the University is in partial compliance with the proposed streamlining of state reform. The conclusion is that the information system deployed shows an improvement in university management in two perspectives: one for management and another in the perception of the users of its services.
\end{abstract}

Keyword: University. Information System. Academic Management. 


\section{INTRODUÇÃO}

Os sistemas de informação, como fundamento para resolução de problemas de gestão, são os grandes desafios para a gestão de organizações estatais. A busca por eficiência nesse tipo de gestão e por melhores resultados advindo dela incentiva este tipo de organização para encontrar soluções à lentidão processual em processos gerenciais já tradicional e comum se encontrar com o nome vulgarmente tratado como "questões burocráticas".

A essência das novas políticas de gestão de estilo empresarial, com a necessidade de gerenciar informações por intermédio de novos sistemas chamados de Sistema Integrado de Gestão Empresarial (enterprise resource planning - ERP) emerge no cotidiano das organizações públicas ou de gestão estatal. Nesse contexto, a Universidade Federal do Pará UFPA lançou o desafio de modernização da gestão no Programa de Desenvolvimento Institucional (PDI) em 2001, visando a modernização da gestão acadêmica e ao mesmo tempo integrar os sistemas existentes que não agregavam as informações das unidades acadêmicas.

A Universidade implantou o Sistema de Informação de Ensino (SIE) em 2006 apresentando modelos de gestão que modificam em velocidade dinâmica e envolvem as pessoas no processo decisório para o alcance da missão organizacional e a uniformidade das informações, originadas da ordem global ERP. Este artigo relata uma pesquisa sobre essa experiência da UFPA, cuja questão principal foi: em que medida o modelo do SIE para gerenciamento administrativos dos assuntos acadêmicos contribuiu para a melhoria de gestão na UFPA?

O objetivo foi identificar de que forma foi implantado o sistema de informação gerencial e que efeitos gerou na comunidade acadêmica durante o processo de implantação. Para dar conta do processo de busca de respostas foi desenvolvida uma pesquisa de caráter descritivo e exploratória, fundamentada em análise de documentos, entrevista semiestruturadas com uso de roteiro e um survey com participantes da implantação do sistema estudado, seja como agentes da implantação ou como usuários. Os referenciais documentais da pesquisa são o programa tecnológico direcionado ao processo de integração de informações de dados acadêmicos da Universidade e instrumento do Plano Nacional de Gestão Pública e Desburocratização (PBQP).

De forma geral os resultados indicam que na experiência de implantação do SIE a elaboração de uma nova forma de atuação atinge diversos níveis administrativos e de tomada de decisão dos gestores que se buscaram criar alternativas de integração e redução dos 
conflitos de informação, especialmente quanto a elaboração de relatórios finais das unidades acadêmicas.

\section{ESTRATÉGIAS DE MUDANÇAS ORGANIZACIONAIS E GERENCIAIS}

Organizações complexas em sua definição nos estudos clássicos (ETZIONI, 1976) são por sua natureza fenômenos de difícil compreensão. Alguns de seus elementos não se desenvolvem da mesma forma nos diferentes tipos de organização. As organizações em geral estão em constante busca para desenvolver atividades de forma mais criativa, eficiente e transformam suas tarefas, processos e métodos por meio do conhecimento, aprimoramento tecnológico ou inovação.

As diferentes concepções de organização se fundamentam na diversidade de unidade de análise, o que amplia a contribuição científica neste campo de estudos. Simon (1970) entende que a organização é uma rede de tomada de decisões. A eficiência dessa rede depende da articulação de diversos fatores estruturais e comportamentais. Levy (1991) chama atenção para o processo de construção de ação coletiva entre atores estratégicos. A construção da ação coletiva geralmente são processos voltados para mudanças de rumo de uma organização.

Na maioria das vezes a administração estratégica aparece como solução. No entanto, a adoção do comportamento estratégico, seja na forma de agir ou planejar esta ação, tem sua origem em fatores externos e internos ao ambiente organizacional, que também resulta do processo de adaptação organizacional (ASTLEY; VAN DE VEN, 2005). A estratégia é resultante da mudança nos dois ambientes e pode ocorrer de forma planejada ou voluntária (MINTZBERG, 1978). Cada organização sofre a pressão por mudança em função de seu ambiente de atuação. Umas sofrem mais pressões internas; outras mais pressões externas.

Em um processo longo e gradual de mudanças organizacionais, a partir dos anos 1960 a 1980, o serviço público transformou práticas, hábitos, valores e rotinas organizacionais, seja de forma planejada endogenamente, como resultado de medidas adotadas, na maioria das vezes normativamente, a partir dos conhecidos "planos de modernização" (BRASIL, 1997) ou de forma induzida, em certa medida pressionada por instituições externas (BORGES, 2000). Fatores como tecnologia, comportamento social, instituições e estruturas influenciam mudanças organizacionais (WOOD JR, 2000). De forma geral, este autor recomenda que a organização deva se ajustar às mudanças conjunturais, políticas e econômicas, às inovações tecnológicas e aprendizagem contínua de seus membros. 
O processo de mudança também é a busca de simplificar e melhorar processos, naquilo que Caulliraux e Yuki (2004) tratam como modelo de gestão como representação simplificada de uma realidade que se pretende entender, controlar e/ou gerenciar (como expõe a Figura 1) e que exige uma visão integrada e sistêmica de gestão.

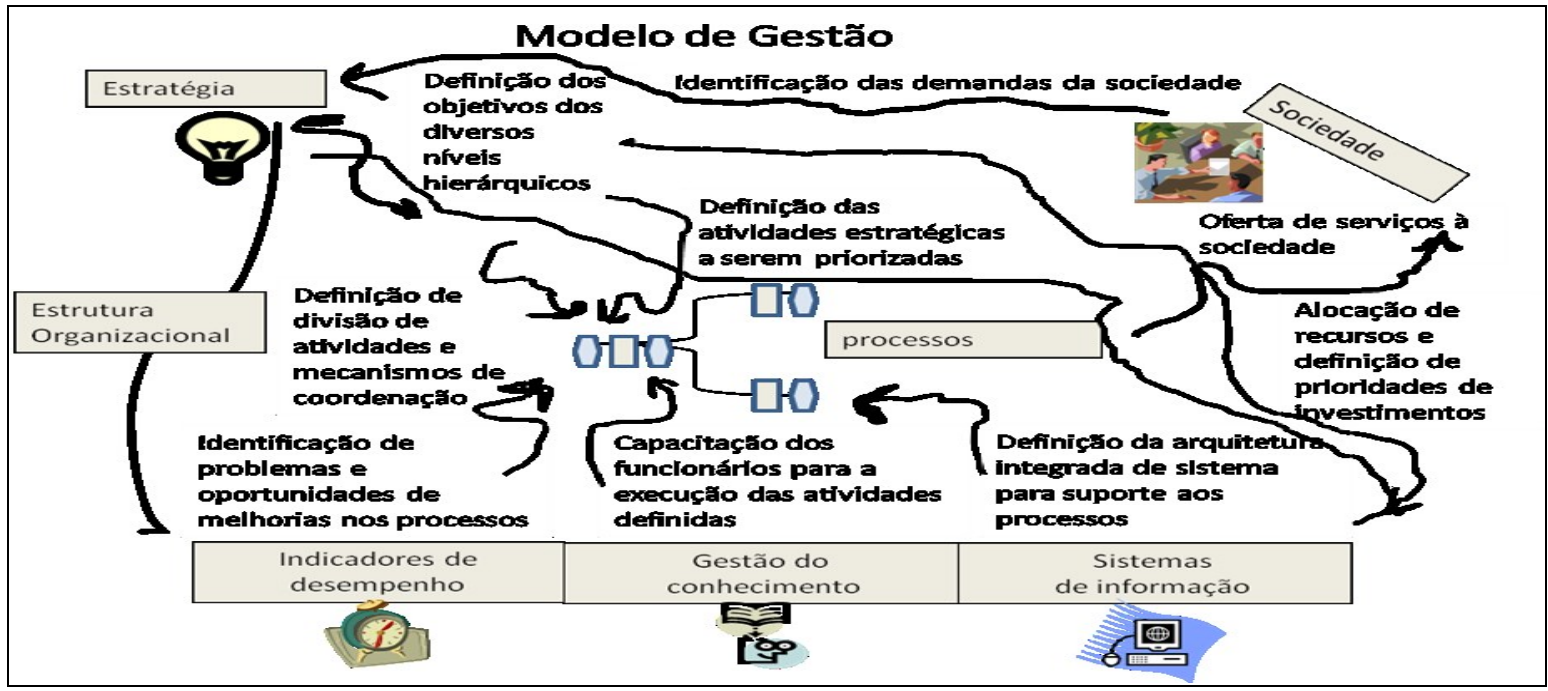

Figura1 Modelo de gestão

Fonte: Adaptado de Caulliraux e Yuki (2004, p. 135).

O modelo de gestão gerencial apresentado por Caulliraux e Yuki (2004) tem como princípio melhorar o desempenho do sistema ao utilizar métodos e procedimentos para controle de produtividade, cuja racionalidade tem como principal preocupação a tomada de decisões, admitindo as limitações pessoais, de tempo e de informações, em busca de alternativas ótimas.

O Modelo de Excelência em Gestão Pública que apresenta como finalidade a busca contínua de melhoria do sistema de gestão tem como uma de suas exigências a autoavaliação. O governo busca a construção de organizações públicas de alto desempenho com foco na satisfação da sociedade como um todo.

A transição informacional pela qual passa o mundo é considerada por Martin (1996) mais devastadora do que a primeira Revolução Industrial. Praticamente em todas as mudanças estruturais de gestão da informação estão presentes a busca pelo aumento da qualidade. Gerentes operam com mais facilidade e aperfeiçoam processos decisórios com o auxílio da tecnologia internacional e de profissionais habilitados para exercerem suas atividades.

Essa interpretação leva a facilidade de compreender o modelo de gestão proposto por Caulliraux e Yuki (2004) para que o sistema informacional interligue ações e indicam 
desempenhos como possibilidades de comunicação não somente pela equipe de apoio, como também com a alta administração e segmentos da sociedade.

É nesse contexto que se dirige a gestão pública para desenvolver políticas públicas que integre a gestão do conhecimento à gestão da informação e à gestão de pessoas. Um dos grandes problemas das mudanças modernas é a implantação de sistemas gerenciais de informação que tão rapidamente tornam-se obsoletos. Para tanto, Pereira (1997) afirma que o sucesso só é garantido quando se predispõe a mudar modelos gerenciais vigentes.

Para acompanhar essas mudanças um planejamento é elaborado com a participação efetiva de gestores nos processos decisórios alinhados aos objetivos da organização levando em consideração que para implantar mudança de oferta de serviços à sociedade é necessário alocar recursos e definir prioridades, entre elas a definição de divisão de atividades e mecanismos de coordenação e a capacitação dos funcionários para a execução das atividades definidas, como apontam Caulliraux e Yuki (2004) em seu modelo de gestão.

\subsection{O PROGRAMA DE QUALIDADE NA ADMINISTRAÇÃO PÚBLICA E A GESTÃO POR RESULTADOS}

O Programa de Qualidade na Administração Pública - PBQP - foi lançado em 1997 e tornou-se o principal instrumento de aplicação do Plano Diretor do Reforma do Estado. Tem como objetivo implantar as mudanças de valores e comportamentos na administração pública federal, incluindo as necessidades estruturais, funcionamento, servidores públicos, condições de trabalho em busca da modernidade (PBQP, 1997). Já o Modelo de Excelência em Gestão Pública (Figura 2), derivado do PBQP, foi criado em 2006 e focou em resultados orientados para o cidadão, ao utilizar a estratégia de adaptação de conceitos e linguagens com manutenção das características, mas com uma diferença de comparar organizações de outros setores. Tem categorias importantíssimas para avaliar como a liderança, estratégias e planos, cidadãos e pessoas, informação e conhecimento, pessoas, processos e por fim resultados. 


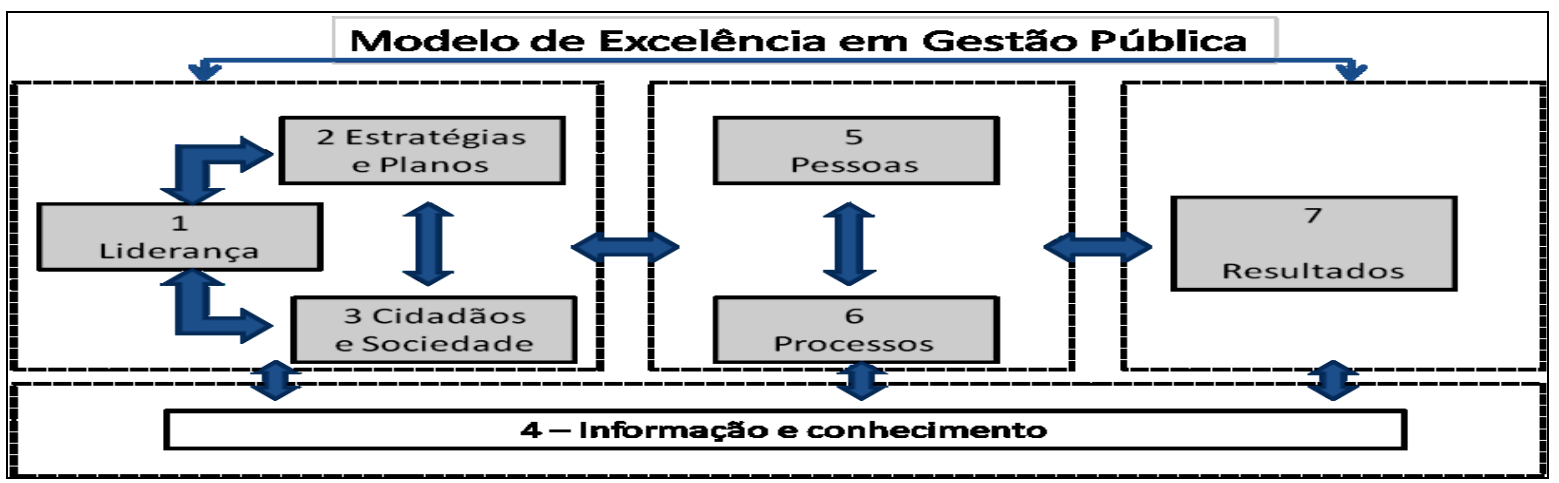

Figura 2- Modelo de Excelência em Gestão Pública

Fonte: Avaliação GesPública 250 pontos.

O modelo busca descobrir se as práticas são inadequadas ou inexistentes; ou as práticas são parcialmente adequadas ou de uso esporádico; ou se as práticas são parcialmente adequadas, em início de implementação; ou se as práticas são adequadas, em início de implementação e, para finalizar se as práticas são adequadas com uso continuado de aplicabilidade.

\subsection{TIPOS DE PROCESSOS EM ORGANIZAÇÕES PÚBLICAS}

A estrutura por processos está relacionada com os novos valores gerenciais e nela se definem responsabilidades, por meio do compartilhamento da tomada de decisão e do conhecimento das atividades, para tentar reduzir os fluxos operacionais e ao mesmo tempo aumentar resultados, ao diminuir a possibilidade de erros.

Esse fato está de acordo com a proposta do Plano Diretor da Reforma do Aparelho do Estado de reduzir entraves da administração burocrática e inserir princípios da administração gerencial, na qual são apresentadas várias mudanças nos arranjos formais e informais com base na eficiência e eficácia. A busca por maior autonomia e flexibilização para dar respostas às demandas administrativas é um dos princípios da mudança de gestão hierárquica para a gestão por contratos (BRESSER-PEREIRA, 2001).

Tais análises relembram a vantagem competitiva levantada por Porter (1989) ao apontar que a competitividade global indica que as organizações devem buscar fortes aparatos tecnológicos com programas que permitam a aplicabilidade de novos métodos de gestão dos processos organizacionais com a inserção de cadeias de valor e que tornam o capital humano fator primordial na competitividade. 


\subsection{TECNOLOGIA DE INFORMAÇÕES (TI) E SISTEMAS DE INFORMAÇÕES (SI)}

Os recursos inteligentes provenientes da era da informação exigem das organizações aparatos sofisticados, rapidez nas tomadas de decisões e transformações nas estruturas dos processos e gerenciamento dos negócios. Se o sistema for bem alimentado com dados confiáveis o resultado final será completo. As pesquisas de Weill e Ross (2006, p. 2) revelam que as empresas de melhor desempenho têm retornos sobre investimentos em TI até 40\% maiores que suas concorrentes e confere proatividade como estratégias de negócio em mudanças organizacionais; aprendem com cada implementação, tornando-se mais hábeis em compartilhar e reutilizar seus ativos ao implantar e controlar as ações os Sistemas Integrados de Gestão (SIG), também denominado de Planejamento dos Recursos da Empresa (ERP).

Queiroz (2007) exemplifica, inclusive, que se deve tomar muito cuidado com o controle de acesso. As senhas de preferência devem ser utilizadas individualmente para aumentar a segurança dos sistemas. Outro item levantado pelo autor é o tipo de veiculação de informações, pois da forma como elas forem processadas, dessa mesma forma elas serão veiculadas. A atenção deve ser redobrada para evitar perda de dados ou até mesmo conflitos internos.

As principais fases de implantação de um sistema ERP, de acordo com Siqueira Neto e Pasqualetto (2011) passam pelas fases de planejamento, onde há Política Integrada de Comprometimento (Meio Ambiente, SSO e Qualidade); a avaliação de riscos (Ambientais, de SSO e de Qualidade); os requisitos legais em todas as esferas do governo e internos de cada empresa; os objetivos/metas e por fim os programas de gestão. E, em seguida, implementam e monitoram; treinam e conscientizam colaboradores; comunicam-se, controlam documentos; controlam operacionalmente; planejam emergências; monitoram e medem; reportam acidentes e não-conformidades; registram e, por fim, a auditoria interna. Enquanto que a última chamada de fase de revisão é realizada a análise crítica da alta administração.

Desta forma a pesquisa pretende compreender de que maneira se deu o processo de implementação do sistema de gestão da informação e quais os benefícios e entraves desse sistema gerencial.

\section{PROCEDIMENTO METODOLÓGICO DA PESQUISA}

A organização objeto da pesquisa foi a UFPA, que conta com 2.309 servidores e desses pelo menos um está em uma das 44 faculdades do Campus Belém e 11 faculdades nos 
campi dos outros municípios, totalizando 55 unidades locais em que se buscou distribuir o levantamento de dados e informações primárias. Além dessas faculdades e campi a UFPA tem cinco núcleos, uma Escola de Aplicação e dois hospitais universitários.

Os procedimentos de pesquisa se desenvolveram da seguinte forma:

a) levantamento documental, como sugerido por Farias Filho e Arruda Filho (2013). Os documentos consultados foram: i) Relatórios das visitas técnicas, Atas, PDI, Relatórios de Gestão, Instrumento para Avaliação da Gestão Pública (Ciclo 2007) e Instrumento para avaliação da Gestão Pública.

b) entrevistas semiestruturadas com gestores das unidades dos campi da capital, de acordo com as orientações de Oliveira (2007). A seleção dos entrevistados foi com base nos seguintes critérios: i) trabalhar diretamente com o sistema estudado; ii) concordar em participar da pesquisa. Os contatos prévios com os potenciais entrevistados foi via email, telefone e pessoalmente, quando não foram possíveis as duas primeiras formas.

c) um survey com uso de questionário fechado, preenchido por servidores que trabalham diretamente com o SIE, seguindo o raciocínio de Yoshino (2010), com uma escala de diferencial semântico bipolar de sete pontos. As questões foram organizadas em cinco blocos (bloco I - perfil do usuário; no bloco II - sobre liderança da GesPública; bloco III - sobre estratégias e planos; bloco IV - sobre necessidades dos grupos de usuários; bloco V - sobre melhoria do desempenho). O Quadro 1 apresenta da distribuição dos sujeitos pesquisados nas unidades da UFPA de acordo com instrumento e técnica de pesquisa.

\begin{tabular}{|c|c|c|c|c|c|c|}
\hline \multirow{2}{*}{$\begin{array}{c}\text { Unidades } \\
\text { Acadêmicas }\end{array}$} & \multicolumn{6}{|c|}{ Pesquisados Segundo Instrumento } \\
\cline { 2 - 7 } & \multicolumn{5}{|c|}{ Questionários } & \multicolumn{4}{|c|}{ Entrevistas } \\
\cline { 2 - 7 } & Gestor & Técnico & Comissão & Gestor & Técnico & Comissão \\
\hline Institutos & 3 & 26 & 2 & 5 & 4 & 1 \\
\hline Campi & 0 & 6 & 0 & 0 & 0 & 0 \\
\hline Total & \multicolumn{3}{|c|}{37 Respondentes } & \multicolumn{3}{|c|}{$\mathbf{1 0}$ Entrevistados } \\
\hline
\end{tabular}

Quadro 1 Pessoas pesquisadas por instrumento e situação funcional Fonte: Pesquisa de Campo (2011-12).

Para análise dos resultados dos questionários foi usada a frequência das respostas e comparadas com o conteúdo das entrevistas. O conteúdo das entrevistas foi selecionado com base nas categorias que constavam nos blocos do questionário, posteriormente retirados trechos e inseridos em uma matriz de análise, na forma como orientam Farias Filho e Arruda Filho (2013), em seguida realizadas as interpretações.

As categorias do GesPública (liderança; estratégia e plano; cidadãos e sociedade; processos e pessoas; resultados; informações e conhecimentos) foram comparadas com as dificuldades administrativas informadas pelos entrevistados, quanto aos objetivos da 
modernização da gestão do PDI da UFPA e quanto a modernização acadêmica, cujo principal eixo está pautado na satisfação do cliente/usuário com busca a eficácia e resultados.

As informações documentais foram interpretadas tendo como referência os processos de implantação do SIE, os relatórios de gestão e as atas das reuniões, utilizando a mesma matriz de análise utilizada para as entrevistas.

\section{RESULTADOS DA PESQUISA}

\subsection{O SISTEMA INTEGRADO DE ENSINO (SIE)}

O SIE é um programa de gerenciamento total que automatiza procedimentos rotineiros, tanto administrativos quanto acadêmicos. Trata-se de um software com a finalidade de auxiliar as universidades nacionais. Possui características que buscam facilitar o acesso de informações, para o público interno (aluno, professor e técnico). Uma das principais características é transformar dados em informações com o Sistema de Gerenciamento e Controle de Acesso (SGCA), conforme Figura 3 do Manual do SIE.

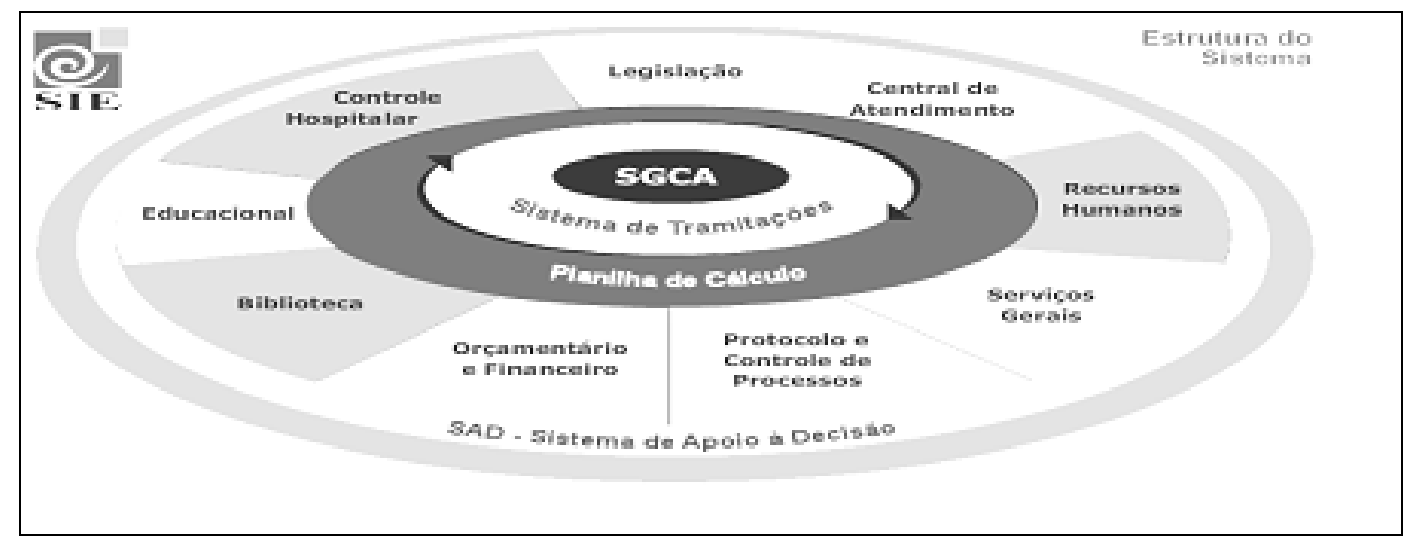

Figura 3 Sistema de Gerenciamento e Controle de Informações da UFPA Fonte: Manual do SIE (2005).

Foi entregue em 2005 por meio de um suporte de armazenamento de informação por rede interna e exemplar impresso. A UFPA o implantou em 2006 e poderia modificar, em função de suas necessidades. Antes da Implantação do SIE foram apresentadas as características do sistema e realizado treinamento para sua operação. As características dos sistemas estão resumidas no Quadro 2 a seguir. 


\begin{tabular}{|c|c|}
\hline Características Favoráveis ao uso do SIE & Características Desfavoráveis ao uso do SIE \\
\hline $\begin{array}{l}\text { - Predomina interação com o discente via Web, no } \\
\text { módulo "Portal do Aluno" (matrícula, consultas, notas, } \\
\text { emissão de histórico). } \\
\text { - É possível gerar o PIT (Plano Individual de Trabalho) } \\
\text { automático e outros relatórios. } \\
\text { - O sistema é parcialmente aberto (permite inserir } \\
\text { modificações). } \\
\text { O SIE está implantado em } 11 \text { IES no país. }\end{array}$ & $\begin{array}{l}\text { - O SIE foi desenvolvido em plataforma "fechada", } \\
\text { compromete o desenvolvimento de aplicações para } \\
\text { interação. } \\
\text { - O SIE trabalha com sistema operacional privado, o que } \\
\text { insere o ônus da aquisição de licenças aos usuários. } \\
\text { - O SIE ainda não possui integração com a Plataforma } \\
\text { Lattes. }\end{array}$ \\
\hline & \\
\hline $\begin{array}{l}\text { ação que se busca há anos na UFPA. } \\
\text { or uma IFES, possui aderência maior } \\
\text { rateleira" } \\
\text { desenvolvimento, manutenção apoio e } \\
\text { tte. }\end{array}$ & $\begin{array}{l}\text { - Ônus com licença de software tanto para o servidor } \\
\text { quanto para os clientes (grande "gargalo" de } \\
\text { implementação). } \\
\text { - Dificuldades no banco de dados com acesso } \\
\text { centralizado. }\end{array}$ \\
\hline $\begin{array}{l}\text { - Tempo estimado de implantação, menor que os } \\
\text { existentes. Envolve, fatores a migração das bases, } \\
\text { adaptação de funcionalidades, implantação dos usuários } \\
\text { e treinamentos. } \\
\text { - Esforço de implantação capacidade da equipe local. } \\
\text { - Capacidade de atendimento em larga escala, em } \\
\text { grandes distâncias geográficas e com disponibilidades de } \\
\text { links de baixas taxas e confiabilidade (características da } \\
\text { UFPA). }\end{array}$ & $\begin{array}{l}\text { - Visita técnica da equipe do SIE que contemple, no } \\
\text { mínimo, duas atividades: } \\
\text { - Reunião de um técnico com outros técnicos da UFPA } \\
\text { que desenvolvem os atuais sistemas definindo a } \\
\text { capacidade e a dificuldade de integração dos atuais } \\
\text { sistemas } \\
\text { - Reunião com amostra dos usuários dos atuais sistemas, } \\
\text { tais como: um funcionário do RH, um da biblioteca, um } \\
\text { do protocolo, um do DERCA, um da PROPESP, um } \\
\text { Coordenador de curso, etc. }\end{array}$ \\
\hline
\end{tabular}

Quadro 2 Características do SIE na UFPA

Fonte: Manual do SIE (2005).

$\mathrm{Na}$ implantação do SIE foi previsto pontos favoráveis e desfavoráveis à apresentação de indicadores de integração, entretanto foi imprescindível que a UFPA desenvolvesse as atividades de processos internos que envolvessem trabalhos manuais, a adequação dos processos de trabalho atuais às mais avançadas técnicas de gestão, o mapeamento dos processos de trabalho a ser implantada, a descrição completa de novos processos de trabalho, o treinamento para os usuários dos novos processos e a implantação dos novos processos junto ao Sistema de Informações Municipais (SIM) da Fundação de Apoio a Tecnologia e Ciência (FATEC).

Como exigência a UFPA deveria providenciar para a equipe técnica, treinamentos, transferência de tecnologia: programação Delphi (básico, avançado e corporativo); manutenção de banco de dados (DB2 ou Oracle; Programação de relatórios no Delphi).

Para o desenvolvimento abrangeria a formação de um grupo de técnicos com dedicação ao desenvolvimento de funcionalidades do SIE, com um numero quantificado para cada caso por depender do volume de novas funcionalidades a serem instaladas, assim como pelos relatórios não instalados no programa. 
Todo processo de implantação seria disponibilizado pela (FATEC) com 430 horas técnicas distribuídas conforme os módulos, sendo que para o ensino ficou em 120h, com a maior carga horária de todos. Todas as atividades foram registradas em atas.

\subsection{ANÁLISE DO MODELO DE GESTÃO E PROCESSO DO SISTEMA INTEGRADO DE ENSINO (SIE)}

A maior dificuldade após a implantação do sistema ainda continua sendo a matrícula de alunos, mesmo com agilidade maior do que o sistema anterior. Dentre os pontos positivos está o acesso melhor controlado com senhas identificadoras do usuário. Dentre as mudanças com a implantação do sistema, estão:

\subsubsection{Categoria Liderança}

a) Acompanhamento dos líderes em reuniões e conhecimento das fases de implantação, assim como o levantamento dos pontos favoráveis e desfavoráveis que foram tratados e analisados com o intuito de evitar riscos e comprometer a utilidade do sistema. Porém, não houve envolvimento dos técnicos, o que dificultou a instalação de módulos que se integrariam ao sistema.

b) Aumentou a competência dos líderes que participaram do processo e treinamentos e muitos dos que participaram repassaram as senhas aos técnicos, mas não repassaram as informações recebidas nos treinamentos gerando um maior grau de insatisfação e conflitos.

c) Foi positivo a inserção dos valores e diretrizes da administração pública e da organização com a elaboração do PDI respeitando o PQBP e consumado o fato de buscar um sistema que promovesse a melhoria do sistema de gestão com agilidade de processos e diminuição de conflitos informacionais.

\subsubsection{Categoria Estratégias e Planos:}

a) $\mathrm{O}$ estabelecimento das fases de implantação com base aos 10 anos de existência do sistema foi apresentado aos eleitos dos Comitês Técnicos, alta administração e FATEC juntamente com os métodos que desdobravam as estratégias e os planos de ações que apresentavam os espaços-temporais estabelecidos no cronograma de execução e que foram monitorados durante toda a execução.

b) Um dos grandes problemas desta categoria reside no fato de que as informações eram diferenciadas e isso dificultava o gerenciamento do processo. 
c) $\mathrm{O}$ fato de o consultor ter dividido o trabalho e responsabilidades auxiliou na execução das tarefas, no entanto houve descontentamentos e ao mesmo tempo satisfação ao final do processo com o aumento dos benefícios oferecidos pelo novo sistema de informação gerencial.

d) Comprovou-se que a alta administração se preocupava em analisar criticamente o desempenho global por meio de monitoramento dos resultados e das queixas. Por isso durante o processo foram tomadas medidas corretivas e de melhorias com a participação do consultor da FATEC que interagiam com reuniões periódicas e continuadas orientadas e comunicadas as partes envolvidas com o sentido de assegurar a efetividade dos valores e diretrizes organizacionais. O Quadro 3 demonstra diferenças entre o SISCA e o SIE obtido por intermédio das entrevistas:

\begin{tabular}{|c|c|}
\hline & SIE \\
\hline $\begin{array}{l}\text { - Implantado em } 1994 \text { para descentralizar tarefas na } \\
\text { matrícula. Acessos ao sistema com possibilidade de } \\
\text { realizar a oferta e matrícula online. Os Campi tinham } \\
\text { dificuldade de acesso, o "tempo não era real" }\end{array}$ & $\begin{array}{l}\text { Implantado em } 2001 \text { para funcionamento } \\
\text { descentralizado e com a inserção de processos } \\
\text { participativos. Todos os Campi acessam em "tempo } \\
\text { real". }\end{array}$ \\
\hline $\begin{array}{l}\text { - Não registrava participações de projetos dos } \\
\text { professores e nem dialogavam entre si. } \\
\text { - O DERCA também contou com a inserção de } \\
\text { programas em cinco Divisões, Protocolo e Secretaria } \\
\text { Administrativa. }\end{array}$ & $\begin{array}{l}\text { Modernamente unificava informações e era usado } \\
\text { há } 10 \text { anos por outras IFES e recebia apoio do } \\
\text { MEC. } \\
\text { Programa de gerenciamento total, que automatiza } \\
\text { procedimentos rotineiros. }\end{array}$ \\
\hline $\begin{array}{l}\text { - Foram criados programas para pedido de vagas, ofertas } \\
\text { de disciplinas e realização de matrícula. }\end{array}$ & $\begin{array}{l}\text { - O módulo Acadêmico facilita os processos que } \\
\text { envolvem professor e aluno, registrando toda a vida } \\
\text { acadêmica dos alunos, com descentralização dos } \\
\text { processos de oferta de disciplinas, matrícula e } \\
\text { lançamento do aproveitamento acadêmico. }\end{array}$ \\
\hline $\begin{array}{l}\text { - Facilidade de funcionamento por meio de } \\
\text { Processamento de dados com a necessidade de alimentá- } \\
\text { los com apenas uma pessoa para gerar relatórios que } \\
\text { eram inconsistentes. } \\
\text { - Matricula podia ser feita por blocos de disciplinas, } \\
\text { transportando os nomes dos alunos para aquele bloco } \\
\text { individual ou matriculando o aluno por disciplina. } \\
\text { - Programa não unificava relatórios. }\end{array}$ & $\begin{array}{l}\text { - Funcionamento que exige mais tempo e pessoas } \\
\text { para alimentar os dados. } \\
\text { - Matrícula pode ser facilitada por bloco de } \\
\text { disciplinas. } \\
\text { - Programa completo por unificar relatórios } \\
\text { consistentes. }\end{array}$ \\
\hline
\end{tabular}

Quadro 3 Diferenças entre o SISCA e o SIE

Fonte: Pesquisa de Campo (2011-12).

\subsubsection{Categoria Cidadão e Sociedade:}

a) Foi diagnosticada com o auxílio de Relatórios de Gestão anteriores a 2005 a necessidade de implantar um sistema que integrasse os sistemas livres existentes, mas não foram consultadas as necessidades dos grupos dos usuários que se sentiram preteridos por não participarem do processo.

b) Os usuários não recebiam informações completas sobre o sistema e foram chamados aos treinamentos sem a devida explicação porque estava sendo mudado 
gerando conflitos e resistências. Não foi avaliada formalmente a satisfação dos seus usuários.

c) O controle social aconteceu com o estabelecimento de senhas de acesso que indica quem manuseou o sistema e registra suas ações.

d) Houve redução do impacto social com a possibilidade de todos terem acesso aos relatórios e ao manuseá-los não necessitam imprimi-los constantemente, reduzindo também os impactos ambientais.

Foram oferecidos treinamentos continuados de acordo com as necessidades dos usuários para tirar dúvidas, mas houve registro de que muitas vezes os treinadores não sabiam como resolver o problema, isso porque o sistema era uma plataforma fechada e somente os consultores da FATEC faziam as alterações processuais por serem protegidas por uso continuado.

Se houvesse maior estímulo as pessoas aceitariam com maior facilidade a mudança do sistema, principalmente por ser mais complexo, exigir maior número de carga horária e mais pessoas no manuseio, afinal eles possuem sua própria preferência como diz Santana (2006). Um entrevistado da Comissão de Implantação disse que "faltou trabalhar melhor o novo sistema com os servidores antes de sua implantação".

Os resultados mostram que os conflitos culturais foram latentes e provocaram resistência aos treinamentos e manuseios do sistema, mas não confere com a utilização do sistema em equipamentos e software obsoleto, nem com a existência de divergências na Comissão de Implantação do SIE.

O SIE por estar em pleno funcionamento no ensino na pesquisa realizando o controle acadêmico. O sistema forneceu suporte necessário para que a organização construísse espaços virtuais com convivência e trocas entre pessoas, promovendo formação profissional e gerando novos conhecimentos. Também interferiu em nova forma de "pensar" a Universidade com a superação das fronteiras espaciais que venceram distâncias com extensão aos campi do estado do Pará. O SIE é instalado e funciona em todos os campi da mesma forma como no campus da capital (Belém) e auxilia em cursos, em serviços formando laços entre a Universidade e os cidadãos que nela atuam.

O processo de criação e implantação do SIE obedeceu a dinâmica que se enquadra na GesPública, pois os resultados mostram a possibilidade de interação entre seus módulos. Mas, há também os pontos desfavoráveis. Por exemplo: o sistema em si não atendeu completamente as necessidades institucionais, mas trouxe avanço significativo em relação ao 
sistema anterior por ter a possibilidade de exercer maior controle do todo e possibilidade de tomar decisões para manter organizadas as informações.

As mudanças na UFPA, a partir do processo de implantação do SIE são notórias, pois em tempo real o usuário recebe informações atualizadas, o que antes não era possível. A GesPública, entretanto aponta que há necessidade de reduzir os entraves burocráticos do sistema, fato notado pelos pesquisados. A realidade existente na UFPA

\section{CONCLUSÃO}

O sistema de informação implantado na Universidade mostra um avanço na gestão universitária, em duas perspectivas: a) a visão gerencial passou a contar com um sistema que auxilia a gestão de processos, embora com limites na participação efetiva de servidores, o que é comum em organizações de gestão estatal, cuja norma jurídica é sempre o parâmetro do que pode e não se pode fazer; b) quanto aos usuários do sistema, houve um ganho considerável de tempo, movido pela agilidade em que as informações passaram a ser de fácil acesso e sem limitações para a melhora dos resultados, já que os principais usuários: professores, gestores e estudantes passaram a usar o sistema integralmente.

A implantação de Sistemas de Informações que se comunicam em tempo real com informações, pessoas e organizações ao mesmo tempo em que são processados dados, permitiu serviços de qualidade. O processo de mudança estatal busca na tecnologia agilidade nas tomadas de decisões, tentando evitar conflitos nas informações que receberam.

Neste caso relatado, a tecnologia diminui distâncias em tempo real. As estratégias e planos foram traçados a partir das divisões por fases que a partir de sua execução iam sendo tomadas medidas corretivas para evitar a falência do sistema. A integração dos sistemas existentes foi permitindo que usuários executem suas atividades no Campus Belém e recebessem informações, ao mesmo tempo, em outros campi.

Entretanto o resultado não foi totalmente o que se esperava, porque os usuários nem sempre conseguiam tirar as dúvidas, em virtude dos treinamentos e das respostas dos treinadores serem insuficientes. Porém, a partir do momento em que começaram a se acostumar com o sistema, passaram a adotar novos comportamentos. Assim, a conclusão é que o sistema promoveu mudanças significativas, mas há ainda forte aparato processual que precisa ser reduzido para se alcançar patamares elevados de eficiência nos processos de gestão da informação. 
O SIE permitiu o avanço na modernização da gestão acadêmica por ele ser um sistema bastante ágil com capacidade de percepção integral de toda a gestão acadêmica promovida pela descentralização das tomadas de decisões.

Mesmo em fase de expansão e de implantação da qualidade, as práticas em início de implantação são adequadas. Existem pontos como o respeito ao estabelecimento de prazos, a maior participação das pessoas no processo, o comprometimento dos gestores em repassarem corretamente as informações, a participação da consultoria nos treinamentos dos usuários e a pesquisa de necessidades antes do fechamento do contrato do sistema, verificando se realmente atenderá aos requisitos organizacionais. Mas nada que não possam ser modificados e melhorados para um próximo momento, como no caso da implantação do outro sistema que substituirá o SIE.

\section{REFERÊNCIAS}

ASTLEY, W. Graham; VAN de VEM, Andrew H. Debates e perspectivas centrais na teoria das organizações. In: Teoria das organizações. (Série RAE-Clássicos). São Paulo: Atlas, 2007.

BORGES, André. Ética burocrática, mercado e ideologia administrativa: contradição da resposta conservadora à "crise de caráter" do Estado. Dados, v.43, n.1, 2000.

BRASIL. Ministério da Administração Federal e Reforma do Estado. Programa da qualidade e participação na administração pública - PBQP. Brasília, DF: MARE, 1997.

BRESSER-PEREIRA, L. C. Do Estado patrimonial ao gerencial. In: PINHEIRO, Wilheim; SACHS (Org.). Brasil: um século de transformações. São Paulo: Cia das Letras, 2001. Disponível: http://www.bresserpereira.org.br/view.asp?cod=509. Acesso em 10.02.2009.

CAULLIRAUX, H. M; YUKI, M. Gestão pública e reforma administrativa: conceitos e casos: a experiência de Florianópolis. Rio de Janeiro: Lucerna, 2004.

ETZIONI, Emitai. Organizações complexas: um estudo das organizações em face dos problemas sociais. São Paulo: Atlas, 1976

FARIAS FILHO, Milton C.; ARRUDA FILHO, Em J. M. Planejamento da pesquisa científica. São Paulo: Atlas, 2013.

LEVY, M. Uma lógica na mudança organizacional. Dados. v. 34, n. 1, p. 79-99, 1991..

Manual de Usuário do Sistema de Informação- SIE. UFPA: Centro de Tecnologia de informação e Comunicação. Disponível: http://www.sie.ufpa.br/manuais.htm. Acesso 23.05.2011. 
MARTIN, James. A grande transição. São Paulo: Editora Futura, 1996

MINTZBERG, H. Padrões na formação da estratégia. Gestão de Ciência, v. 29, n. 9, p.93448, 1978.

YOSHINO, C. K. N. Fatores críticos de sucesso como antecedentes da aceitação de um sistema de informações em uma universidade federal. (Dissertação Mestrado), Centro de Ciências Sociais Aplicadas, Universidade Federal do Rio Grande do Norte, Natal, 2010.

OLIVEIRA, Maria M. de. Como fazer pesquisa qualitativa. Petrópolis: Vozes, 2007.

PEREIRA, Maria José Lara de Bretas; FONSECA, João Gabriel Marques. Faces da Decisão: as mudanças de paradigmas e o poder da decisão. São Paulo: Makron Books, 1997.

PORTER, Michel E. A vantagem competitiva das nações. Rio de Janeiro: Campus, 1989.

QUEIROZ. C. C. Segurança digital um estudo de caso. Fortaleza: Faculdade de Lourenço Filho, 2007. Disponível http://www.flf.edu.br/revista-flf/monografiascomputacao/seguranca_digital.pdf. Acesso 13.04.2009.

SANTANA, C. C. de A. O modelo gerencial do controle interno governamental: as melhores práticas de Pernambuco. Rio de Janeiro: FGV, 2010.

SIMON. H. A. Comportamento administrativo. Rio de Janeiro: FGV, 1970.

SIQUEIRA NETO, Nelson; PASQUALETTO, Antônio. Modelo para fase de planejamento de um sistema integrado de gestão em usinas de cana-de-açúcar. Goiás: PUC. (2011). Disponível: http://www.pucgoias.edu.br/ucg/prope/cpgss/ArquivosUpload/36/file/MODELO$\% 20$ PARA $\% 20$ FASE $\% 20$ DE $\% 20$ PLANEJAMENTO $\% 20$ DE $\% 20$ UM $\% 20$ SISTEMA $\% 20 \mathrm{IN}$ TEGRADO $\% 20 \mathrm{D} \% \mathrm{E} 2 \% 80 \%$ A6.pdf. Acesso em 26.08.2009.

UNIVERSIDADE FEDERAL DO PARANÁ (UFPR). Comissão Universidade XXI: fundamentos para uma nova política de ensino superior. Curitiba: UFPR, 2003.

WEILL, P. e ROSS, Jeanne W. Governança de tecnologia da informação. São Paulo: M. Books do Brasil, 2006.

WOOD JUNIOR, Thomaz; CALDAS, Miguel P. Modismos em Gestão: pesquisa sobre a adoção e resources planning: evolução, conceitos e estrutura. In: ENCONTRO NACIONAL DE ENGENHARIA DE PRODUÇÃ̃O, 20., 2000. São Paulo. Anais...2000. São Paulo:Universidade de São Paulo, 2000. 